\title{
Synergistic inhibition of tumor cell proliferation by metformin and mito-metformin in the presence of iron chelators
}

\author{
Gang Cheng ${ }^{1,2}$, Jacek Zielonka ${ }^{1,2,3}$, Micael Hardy ${ }^{7}$, Olivier Ouari ${ }^{7}$, Christopher R. \\ Chitambar ${ }^{1,4}$, Michael B. Dwinell ${ }^{3,5,6}$ and Balaraman Kalyanaraman ${ }^{1,2,3}$ \\ ${ }^{1}$ Department of Biophysics, Medical College of Wisconsin, Milwaukee, WI 53226, USA \\ ${ }^{2}$ Free Radical Research Center, Medical College of Wisconsin, Milwaukee, WI 53226, USA \\ ${ }^{3}$ Cancer Center, Medical College of Wisconsin, Milwaukee, WI 53226, USA \\ ${ }^{4}$ Department of Medicine, Medical College of Wisconsin, Milwaukee, WI 53226, USA \\ ${ }^{5}$ Department of Microbiology and Immunology, Medical College of Wisconsin, Milwaukee, WI 53226, USA \\ ${ }^{6}$ Department of Surgery, Medical College of Wisconsin, Milwaukee, WI 53226, USA \\ ${ }^{7}$ Aix Marseille University, CNRS, ICR, UMR 7273, Marseille 13013, France \\ Correspondence to: Balaraman Kalyanaraman, email: balarama@mcw.edu
}

Keywords: iron chelators; mitochondria-targeting agents; cancer cell proliferation; biguanide; metformin analogs

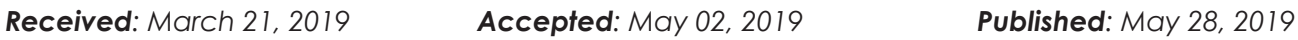

Copyright: Cheng et al. This is an open-access article distributed under the terms of the Creative Commons Attribution License 3.0 (CC BY 3.0), which permits unrestricted use, distribution, and reproduction in any medium, provided the original author and source are credited.

\section{ABSTRACT}

We demonstrate that combined treatment with metformin (Met) or its mitochondria-targeted analog, mito-metformin (Mito-Met), and various iron chelators synergistically inhibits proliferation of pancreatic and triple-negative breast cancer cells. Previously, we reported that Met (at millimolar levels) and Mito-Met (at micromolar levels) inhibited pancreatic cancer cell proliferation. Inhibition of mitochondrial complex I and mitochondrial oxidative phosphorylation (OXPHOS) through stimulation of mitochondrial redox signaling was proposed as a key mechanism for decreased cancer cell proliferation. Because of its poor bioavailability, the use of Met as a "stand-alone" antitumor drug has been questioned. Iron chelators such as deferasirox (DFX) and dexrazoxane (DXR) exhibit antiproliferative effects in cancer cells. The potency of Met and Mito-Met was synergistically enhanced in the presence of iron chelators, DFX, N,N'-bis(2-hydroxyphenyl)ethylendiamine- $N, N$ 'diacetic acid (HBED), and deferoxamine (DFO). Met, DXR (also ICRF-187), and DFO are FDA-approved drugs for treating diabetes, decreasing the incidence and severity of cardiotoxicity following chemotherapy, and mitigating iron toxicity, respectively. Thus, the synergistic antiproliferative effects of Met and Met analogs and iron chelators may have significant clinical relevance in cancer treatment. These findings may have implications in other OXPHOS-mediated cancer therapies.

\section{INTRODUCTION}

Metformin (Met), a synthetic biguanide analog of guanidines found in Galega officinalis and an FDAapproved drug, is one of the most widely used antidiabetic drugs (Figure 1) [1]. Although the bioavailability of Met is poor, it has a very good safety profile, and diabetic patients typically tolerate daily doses of gram quantities of the drug [2]. Recent studies suggest that diabetic patients taking Met exhibit a decreased incidence of pancreatic cancer $[3,4]$. Several clinical trials are currently underway exploring the possibility of repurposing Met as a potential antitumor drug in other cancers $[5,6]$. A prevailing view is that Met targets mitochondria, albeit weakly; inhibits complex I in the mitochondrial electron transport chain; and activates the "AMPK/mTOR pathway" involved in regulating cellular metabolism, energy homeostasis, and cell growth [7,8]. Although Met is relatively safe, the plasma concentration reaches only a few micromolar, even at high doses (500-1,000 mg/day), in humans. This raises a concern about the therapeutic feasibility for Met to act as an effective antitumor agent. There is a critical 
need to enhance the antitumor potency of Met through combinatorial drug therapy. To this end, analogs of Met (Mito-Met) conjugated to varying alkyl chain lengths containing a triphenylphosphonium cation $\left(\mathrm{TPP}^{+}\right)$were synthesized and characterized [7]. The Mito-Met analog (e.g., Mito-Met shown in Figure 1) was nearly 1,000 times more effective than Met in inhibiting pancreatic cancer cell proliferation in vitro and tumor progression in vivo [7].

Both Met and Mito-Met exert a potent radiosensitizing effect in tumor cells [7, 9, 10]. MitoMet was significantly more effective than metformin in enhancing cancer cell radiosensitivity [7]. Iron chelators induce an antiproliferative effect in tumor cells by causing cell cycle arrest [11]. Iron chelators with high antiproliferative activity also upregulate the expression of a tumor suppressor gene [12]. Thus, we postulated that combining iron chelators with mitochondria-targeted drugs (e.g., Met or Mito-Met) will induce synergistic antiproliferative effects in cancer cells. Tumor cells have different levels of hypoxic areas, with the central core exhibiting maximal hypoxia $[13,14]$. However, most in vitro experiments on cancer cells are performed under normoxic conditions, and the results obtained under such conditions may be different from results from the same experiments conducted at lower oxygen tensions. Several FDA-approved iron chelators including deferoxamine (DFO), a hexadentate chelator, and deferasirox (DFX), a tridentate chelator (Figure 1), target both proliferating and quiescent cells [15-17]. Thus, the potential for clinical translation of the combined use of Met and iron chelators in cancer treatment is high. In this study, we report that treatment of pancreatic and triple-negative breast cancer cells with Met and Mito-Met and selected structurally different iron chelators exerts synergistic antiproliferative effects. Because some of these compounds are FDAapproved and orally effective drugs, their clinical application in cancer treatment is possible.

\section{RESULTS}

\section{Inhibition of pancreatic cancer cell proliferation by iron chelators and metformin analogs}

We determined the antiproliferative effects of the combination of Met or Mito-Met with structurally different chelators: DFX, an orally available iron chelator used for treatment of iron overload; dexrazoxane (DXR), which protects against doxorubicin-induced cardiotoxicity; and 3-AP (also called Triapine), an experimental anticancer drug and a potent inhibitor of ribonucleotide reductase. Figure 2 shows the antiproliferative effect of DFX and Met or Mito-Met in MiaPaCa-2 cells. The strongest antiproliferative effects were observed using the combination of Met or Mito-Met with the DFX chelator. Next, we investigated the combinatorial effects of Met or Mito-Met in the presence of DXR in PANC1 cell proliferation. Again, the strongest antiproliferative effects were detected for Mito-Met and iron chelator (Supplementary Figure 1). Strong potentiation of antiproliferative effects of metformin by iron chelators<smiles>CN(C)C(N)=NC(=N)N</smiles>

Metformin (Met)<smiles>NC(=S)N/N=C/c1ncccc1N</smiles>

Triapine (3-AP)<smiles></smiles>

Mito-metformin (Mito-Met)<smiles>O=C(O)c1ccc(-n2nc(-c3ccccc3O)nc2-c2ccccc2O)cc1</smiles>

Deferasirox (DFX)<smiles>O=C(O)CN(CCN(CC(=O)O)Cc1ccccc1O)Cc1ccccc1O</smiles>

HBED<smiles>C[C@H](CN1CC(=O)NC(=O)C1)N1CC(=O)NC(=O)C1</smiles>

Dexrazoxane (DXR)

Figure 1: Chemical structures of iron chelators, Met, and Mito-Met used in this study. 
was also observed in the case of AsPC-1, a second human pancreatic cancer cell line (Supplementary Figure 2), and FC-1242, a murine pancreatic cancer cell line isolated from spontaneous KRAS-p53 mutant pancreatic tumors [18] (Supplementary Figure 3).

\section{Synergistic antiproliferative effect of iron chelators and Met in breast cancer cells}

We determined the synergistic antiproliferative effects of the iron chelator, DFX, and Met on breast cancer cells. Triple-negative breast cancer cells, MDA-MB-231, and brain homing breast cancer cells, MDA-MB-231$\mathrm{BR}$, were treated with Met or DFX alone and together. Cell proliferation was monitored in real time and showed that the combination of DFX and Met inhibits more than additively (Figure 3 ). Other iron chelators (e.g., N,N'-
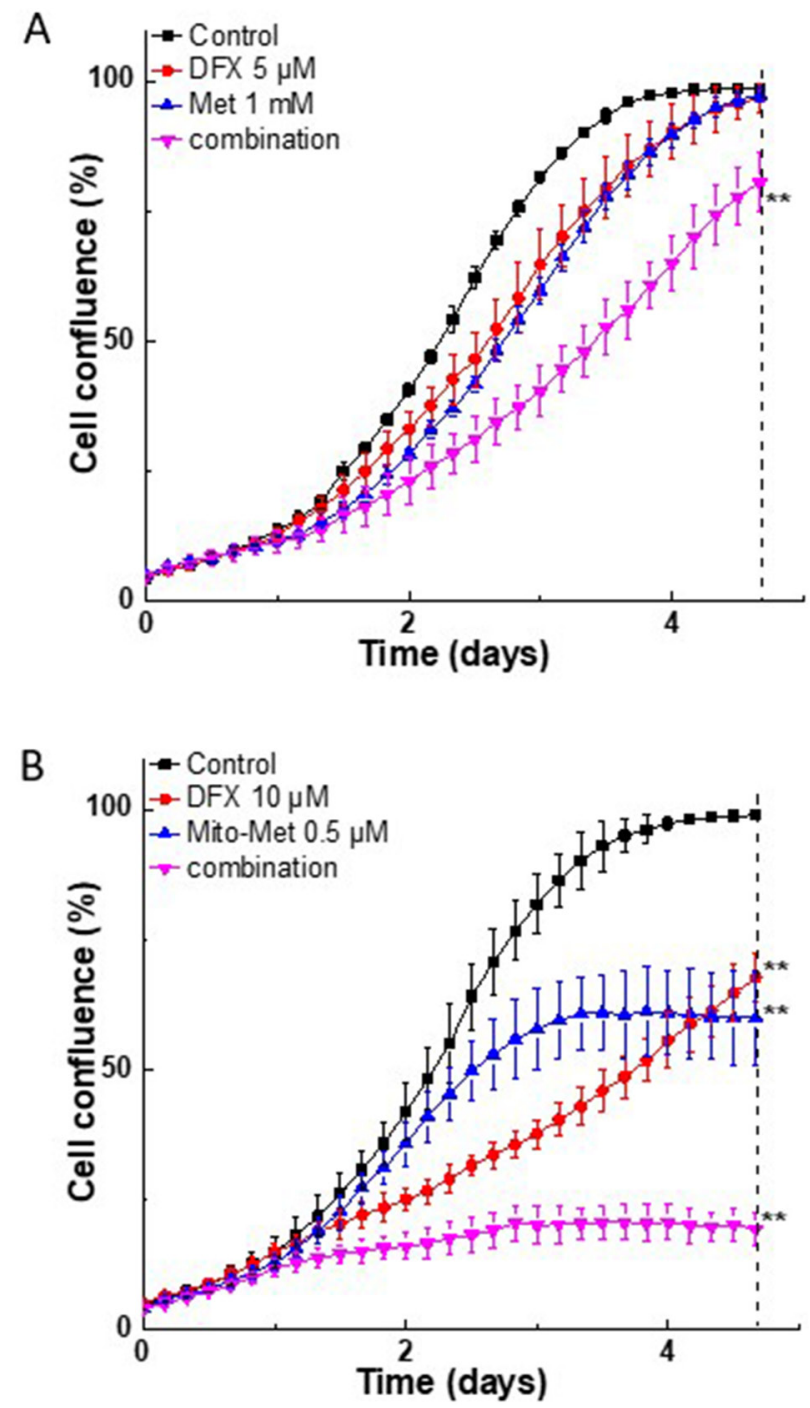

bis(2-hydroxyphenyl)ethylendiamine-N,N'-diacetic acid [HBED]) dose-dependently decreased the survival fraction of MDA-MB-231 breast cancer cells (not shown).

\section{Quantitative analyses of the synergy between iron chelator, HBED, and metformin analogs in the inhibition of MiaPaCa-2 cell proliferation}

We monitored the effect of the compounds studied on the proliferation of $\mathrm{MiaPaCa}-2$ pancreatic cancer cells in real time using the IncuCyte Live-Cell Imaging system. Figure 4A shows the antiproliferative effects of Met (left) and Mito-Met (right) and the iron chelator, HBED, either alone or in combination in pancreatic cancer cells, MiaPaCa-2. At the concentration of the compounds, which had only modest effects when used alone, the combination of Met or Mito-Met with HBED chelator led
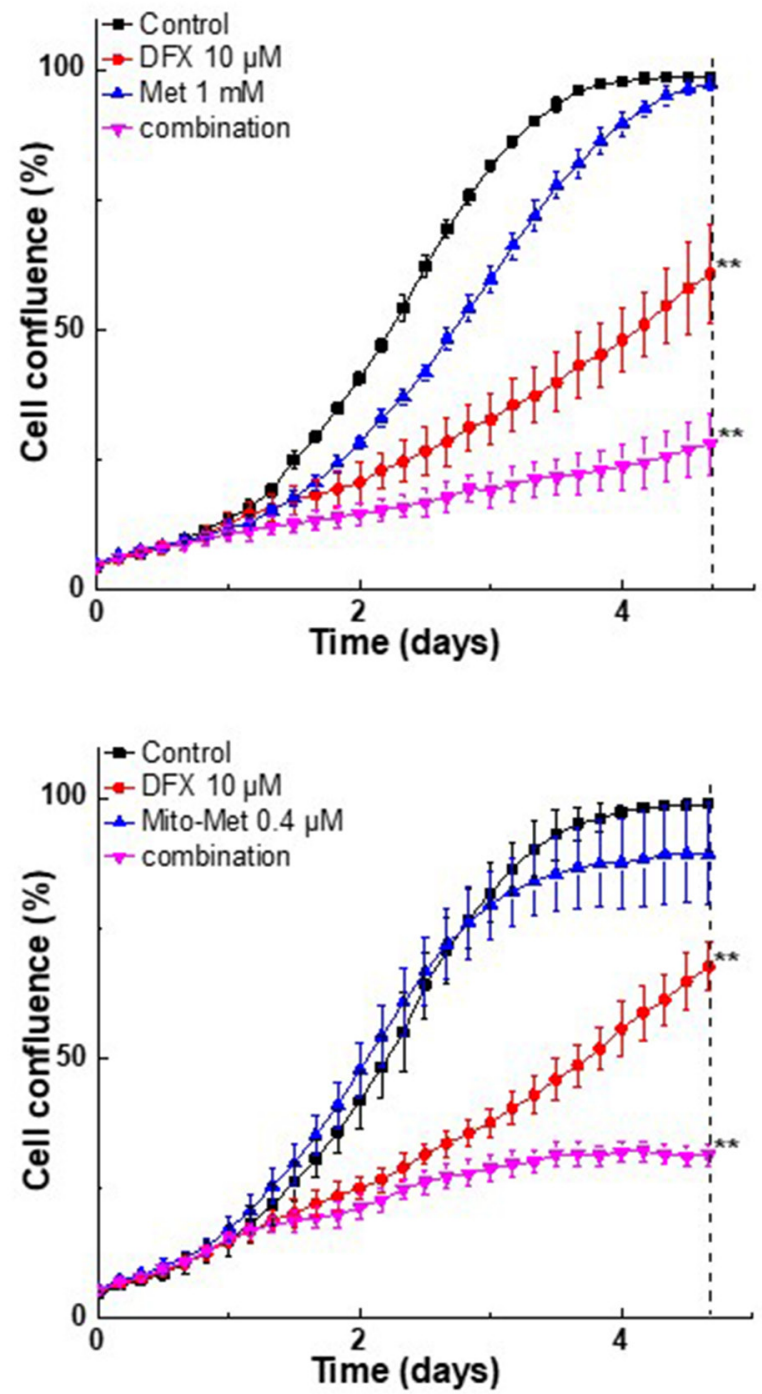

Figure 2: Effect of Met, Mito-Met, and iron chelator, DFX, on MiaPaCa-2 cell proliferation. Cells were treated with DFX $(5$ or $10 \mu \mathrm{M})$ and Met $(\mathbf{A}$, left and right) or Mito-Met (B, left and right) independently and together, as indicated, and cell growth was monitored continuously. Data shown are the mean $\pm \mathrm{SD}(n=4)$. The dotted vertical lines indicate the time points at which the level of significance was calculated $\left({ }^{* *} P<0.01\right)$. 
to stronger antiproliferative effects. Next, we investigated the concentration-dependent effect of the combination of the above compounds on cell proliferation. The cell confluence (as control groups reach $90 \%$ confluency) was plotted against the concentrations of the drugs. Figure 4B shows a three-dimensional heat map representation of the dependence of cell confluence on the concentrations of Met and HBED (left) and Mito-Met and HBED (right), alone and in combination. Figure 4C depicts the combination index-fraction affected (CI-Fa) plots. The CI parameter is a measure of the synergy, with values below one indicating synergy, a value of one indicating additive effects, and values above one indicating drug antagonism. The Fa parameter is used as a measure of the drug's efficacy, with a value of one indicating total inhibition of cell proliferation and a value of zero indicating the lack
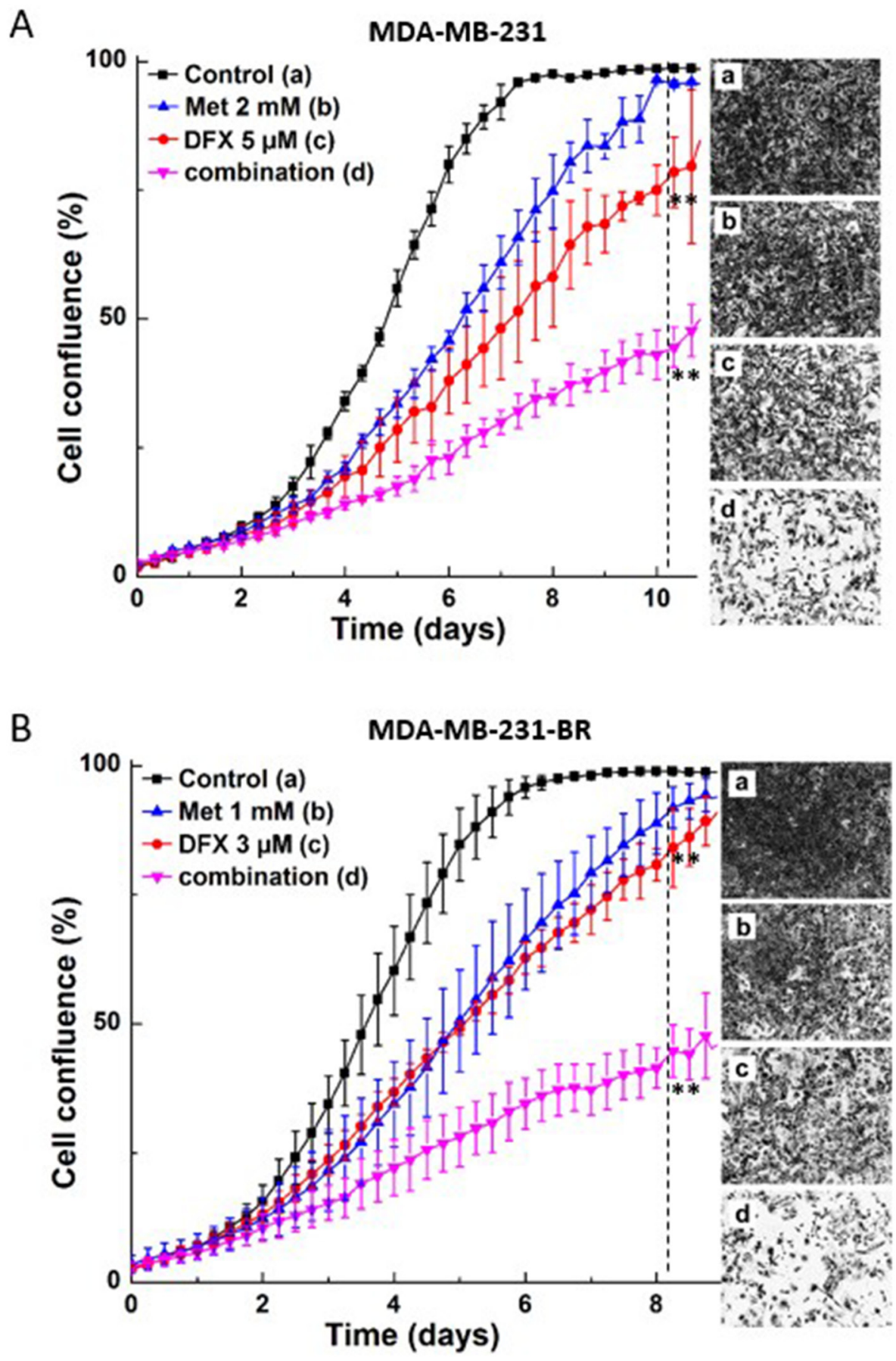

Figure 3: Effect of Met and iron chelator, DFX, on MDA-MB-231 and MDA-MB-231-BR cell proliferation. Cells were treated with DFX or Met independently and together, as indicated; MDA-MB-231 (A) and MDA-MB-231-BR (B) cell growth was monitored continuously. Data shown are the mean $\pm \mathrm{SD}(n=4)$. The dotted vertical lines indicate the time points at which cell pictures were taken and the statistical significance was calculated $\left({ }^{* *} P<0.01\right)$. 
of effect of the treatment on cell confluence. As shown in Figure 4C, both Met (left) and Mito-Met (right) exert synergistic inhibition of cell proliferation at several concentrations $(1-10 \mu \mathrm{M})$ of HBED.

\section{Effect of Met and Mito-Met on colony formation by MiaPaCa-2 cells}

MiaPaCa-2 cells were treated with Met or MitoMet in the presence of HBED, and the number of colonies formed was counted. As shown in Figure 5A (left), the number of colonies formed in the presence of Met and HBED was decreased. The survival fraction was calculated and a significant decrease in survival of MiaPaCa-2 cells was obtained, with the strongest and statistically significant inhibition observed when the drugs were combined (Figure 5A, right). Figure 5B (left and right) shows that Mito-Met and HBED also significantly decreased pancreatic cancer cell colony formation, except that Mito-Met was effective at micromolar concentrations as compared with Met, present at millimolar levels. MitoMet is nearly 1,000-fod more effective than Met.

\section{Effect of iron chelators and Met analogs on mitochondrial complex I activity, ROS formation}

Because iron chelators and Met analogs effectively induced synergistic inhibitory effects on cancer cell proliferation, we tested their effects under these conditions on mitochondrial function (Figure 6A, 6B). As reported previously [7], both Met (millimolar concentration) and Mito-Met (micromolar concentration) inhibited the mitochondrial complex I-mediated oxygen consumption rate (OCR) in MDA-MB-231 cells (Figure 6C). However, at $100 \mu \mathrm{M}$ concentration, equal to or higher than the one that exacerbated the antiproliferative effects of Met and Mito-Met, the iron chelators, HBED, 3-AP, or DXR, did not inhibit mitochondrial complex I-dependent OCR in MiaPaCa-2 and MDA-MB-231 cells (Figure 6A, $6 \mathrm{~B})$. It was previously reported that, at much higher concentrations (1 $\mathrm{mM})$, DFO inhibited mitochondrial respiration in neuroblastoma cells [19]. From these results, we conclude that iron chelators and Met/Mito-Met do not induce a synergistic inhibition of OCR in cancer cells.

The superoxide $\left(\mathrm{O}_{2}{ }^{-}\right)$-specific probe, hydroethidine (HE), was used to detect Mito-Met-induced superoxide generated by inhibiting complex I in MiaPaCa- 2 cells (Figure 7) [20]. In addition to $\mathrm{O}_{2}^{-}$, Mito-Met induced peroxidatic oxidants as determined by monitoring the increase in nonspecific oxidation product, ethidium cation $\left(\mathrm{E}^{+}\right)$, and peroxidase-catalyzed formation of dimers (diethidium $\left[\mathrm{E}^{+}-\mathrm{E}^{+}\right]$) (Figure 7A, 7B). Inclusion of the iron chelator, HBED, did not affect Mito-Met-induced formation of these reactive oxygen species (ROS)-specific and nonspecific oxidation products of HE. These results rule out the possible role of ROS as a potential mechanism for the synergistic antiproliferative effect of iron chelators and Met analogs.

\section{Role of hypoxia on Met/Mito-Met- and iron- chelator-induced effects}

It was reported that the effect of iron chelator DFX observed at low oxygen levels is not the same as those obtained under high oxygen levels in human glioblastoma cells [21]. For example, the iron chelator DFX inhibited the proliferation of glioblastoma cells under normoxic conditions; however, this effect was reversed under low oxygen tension $\left(3 \% \mathrm{O}_{2}\right)$ [21]. Thus, we investigated the effect of hypoxia $\left(1 \% \mathrm{O}_{2}\right)$ on the antiproliferative potency of DFX in MiaPaCa-2 cells. As shown in Figure 8A, DFX $(30 \mu \mathrm{M})$ significantly inhibited cell proliferation under normoxia $\left(20 \% \mathrm{O}_{2}\right)$. However, under hypoxic conditions $\left(1 \% \mathrm{O}_{2}\right)$, the inhibitory effect on cell proliferation was abolished (Figure 8B). This is consistent with the previous report using glioblastoma cells [21]. Conversely, when combined, both Met and DFX as well as Mito-Met and DFX, inhibited cell proliferation even under $1 \% \mathrm{O}_{2}$ (Figure 8C). This is consistent with our previous study, which showed that hypoxic conditions did not reverse the inhibitory effect of Met or Mito-Met in pancreatic cancer cells [7].

\section{DISCUSSION}

In this work, we discovered that several FDAapproved iron chelators can synergistically enhance the antiproliferative potency of relatively nontoxic drugs, Met and Mito-Met mitochondria-targeted analog, in pancreatic and triple-negative breast cancer cells. These findings could have significant clinical and translational impact on the application of Met and Mito-Met and related analogs in cancer chemotherapy and radiation therapy.

\section{Iron chelators and anticancer effects}

The role of iron and ROS in cancer tumor proliferation and tumor growth and metastasis is paradoxical $[22,23]$. Tumor cells require more iron than normal cells to sustain increased demands for energy, protein function, and DNA synthesis. For example, the activity of ribonucleotide reductase (RR), a key enzyme that catalyzes the conversion of ribonucleotides to deoxyribonucleotides, depends on the presence of iron in its M2 subunit [24, 25]. Since the RRM2 subunit in mammalian cells has a half-life of $\sim 4$ hours, a steady supply of iron is needed for RR activity. Limitation of iron availability to RRM2 inhibits RR activity and blocks DNA synthesis. Tumor cells exhibit increased expression and activity of RR as well as increased expression of the transferrin receptor at the cell surface, enabling enhanced cellular uptake of iron [26]. Iron chelators exert 

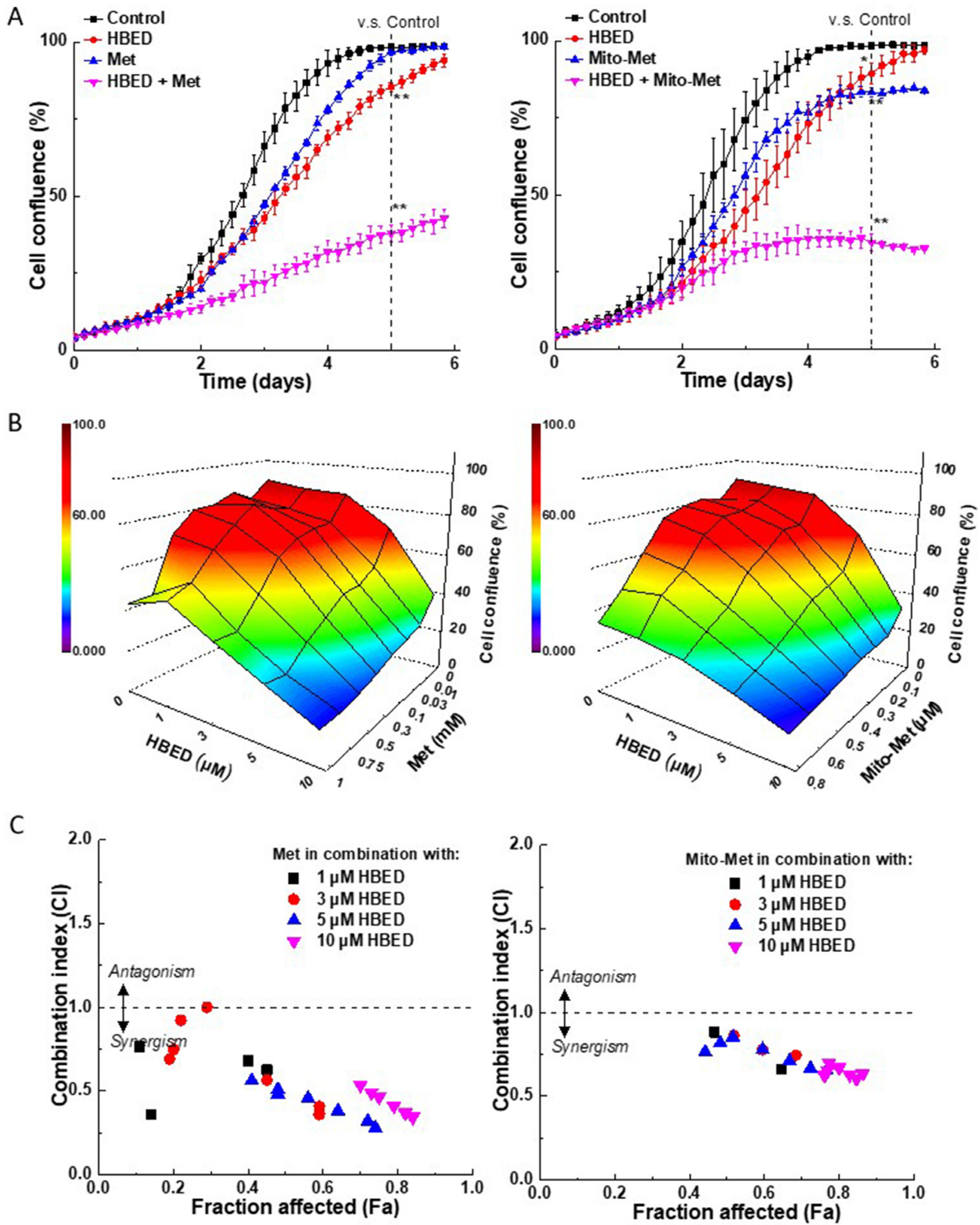

Figure 4: Synergy analyses of the effect of the combination of iron chelator, HBED, with Met, or Mito-Met on MiaPaCa-2 cell proliferation. (A) MiaPaCa- 2 cells were treated with $\mathrm{HBED}(5 \mu \mathrm{M})$ or Met $(0.5 \mathrm{mM}$, left $)$, Mito-Met $(0.4 \mu \mathrm{M}$, right) independently and together and cell growth monitored continuously. Data shown are the mean $\pm \mathrm{SD}(n=3)$. The dotted vertical lines indicate the time points at which the levels of significance were calculated $\left({ }^{* *} P<0.01\right)$. (B) Effects of Met (left) and Mito-Met (right) on cell proliferation. The cell confluence (as control groups reach $90 \%$ confluency) is plotted as a three-dimensional representation showing the concentration-dependent effects of HBED, Met, or Met analog alone and together on cell proliferation. Panel (C) shows the CI-Fa plots. The fraction affected parameter is used as a measure of the drug's efficiency, with a value of one indicating complete inhibition of cell confluence and a value of zero indicating a lack of effect on cell confluence. 
antiproliferative effects in vitro and in vivo on various cancers through inhibition of RR [27, 28]. Alternatively, inhibiting transferrin-receptor-dependent iron uptake also results in inhibition of RR and of tumor cell proliferation $[29,30]$. We tested the effect of hydroxyurea (RR inhibitor) and Met analogs on pancreatic cancer cell proliferation (Supplementary Figure 4). Results indicate that there was no synergistic effect on cell proliferation, suggesting that $\mathrm{RR}$ inhibition is not responsible for the synergistic effect observed with iron chelator and Met analogs.

Enhanced intracellular iron can increase lipid peroxidation via the Fenton-type reaction and release of electrophilic metabolites that can stimulate apoptosis or ferroptosis of cancer cells [31]. Overexpression of glutathione-dependent peroxidase that supports the detoxification of lipid hydroperoxides inhibits ferroptosismediated cancer cell death [32]. Iron chelators could potentially thwart ferroptosis by inhibiting the Fenton-type reaction and exerting pro-tumorigenic effects [33]. Thus, the ultimate effect of iron chelators may depend on several factors, including the timing of treatment, activity of redox enzymes, and type of cancer cells.

Recently, it was reported that clinically relevant antioxidant drugs (vitamin $\mathrm{E}$ and $\mathrm{N}$-acetyl cysteine) enhance metastasis of tumors by decreasing ROS [34]. Iron chelation did not significantly affect Mito-Met-
A

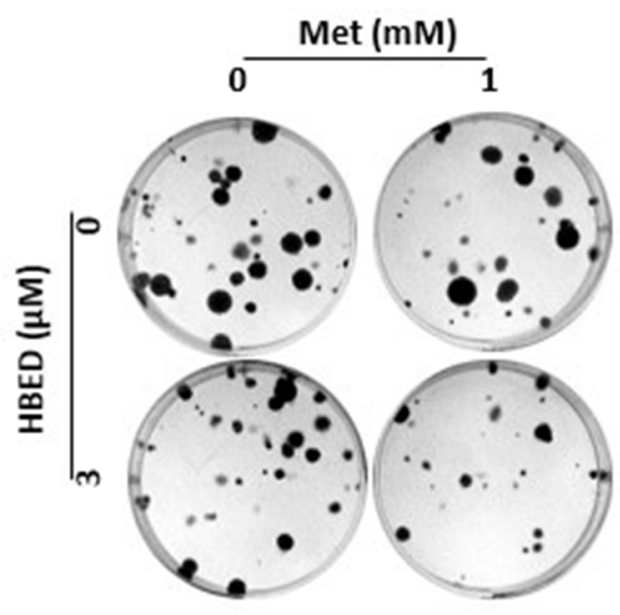

B

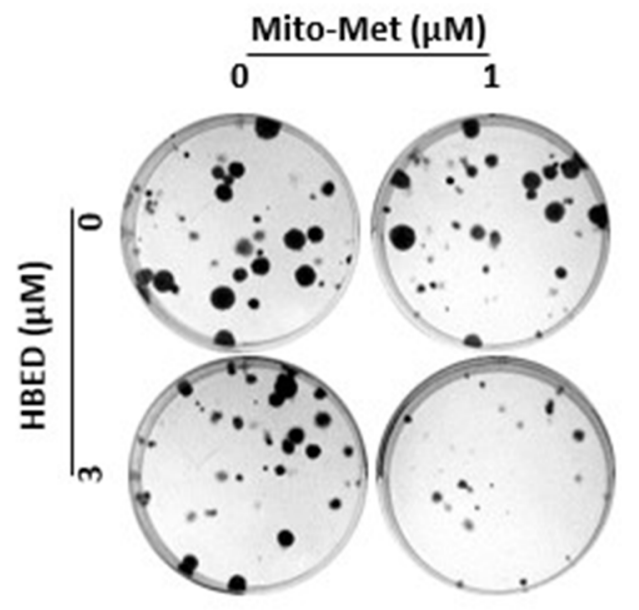

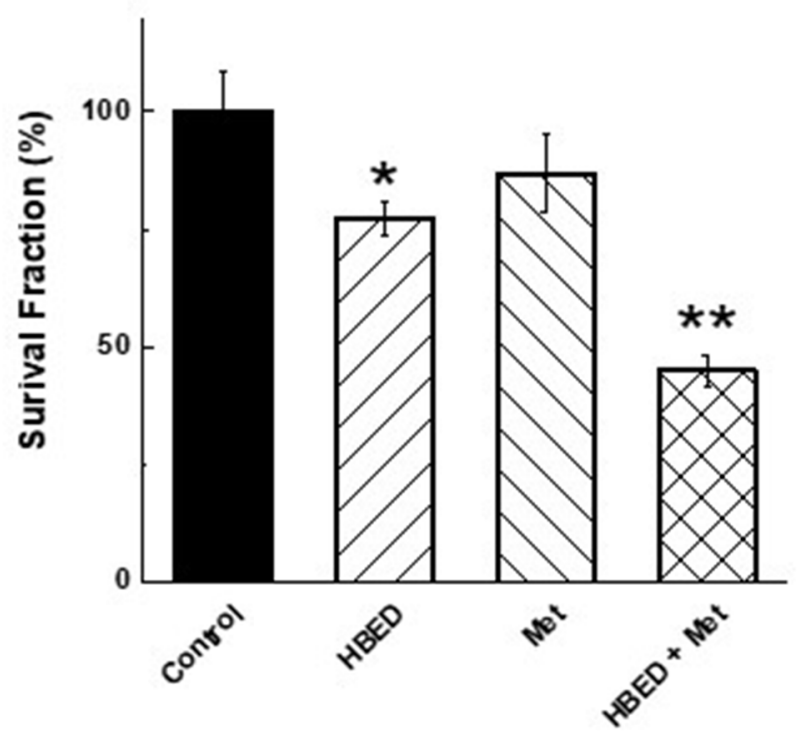

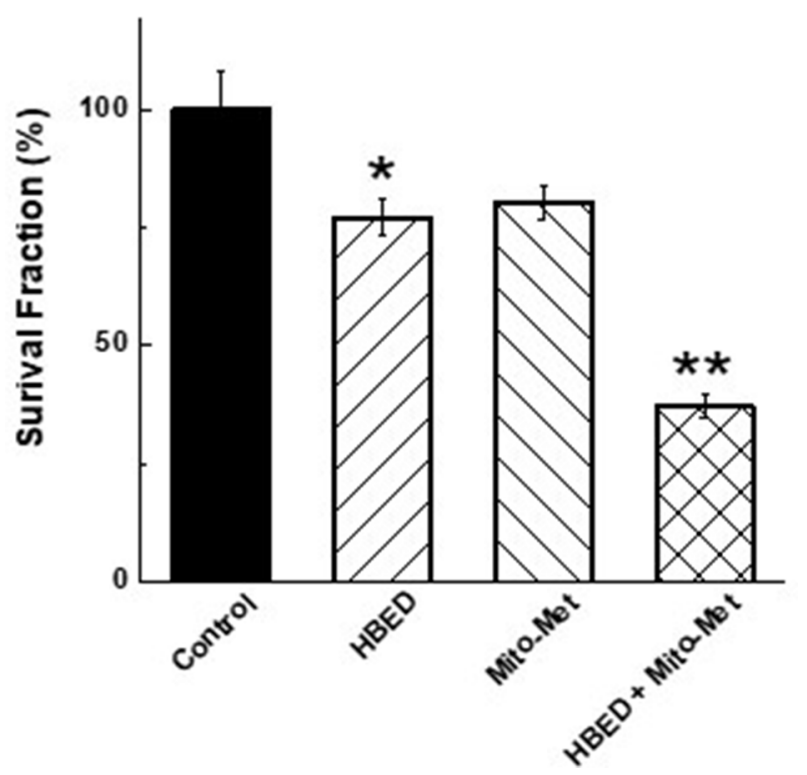

Figure 5: Effect of Met, Mito-Met, and HBED on colony formation by MiaPaCa-2 cells. (A) MiaPaCa-2 cells were treated with HBED $(3 \mu \mathrm{M})$, Met $(1 \mathrm{mM})$ alone or together, the colony formation was monitored (left), the number of colonies counted, and the survival fraction calculated (right). (B) Same as in (A), but Mito-Met $(1 \mu \mathrm{M})$ was used instead of Met. Data shown represent the mean \pm SEM. ${ }^{*} P<0.05(n=6)$ comparing the HBED/Mito-Met or HBED/Met combination to HBED alone. 
A
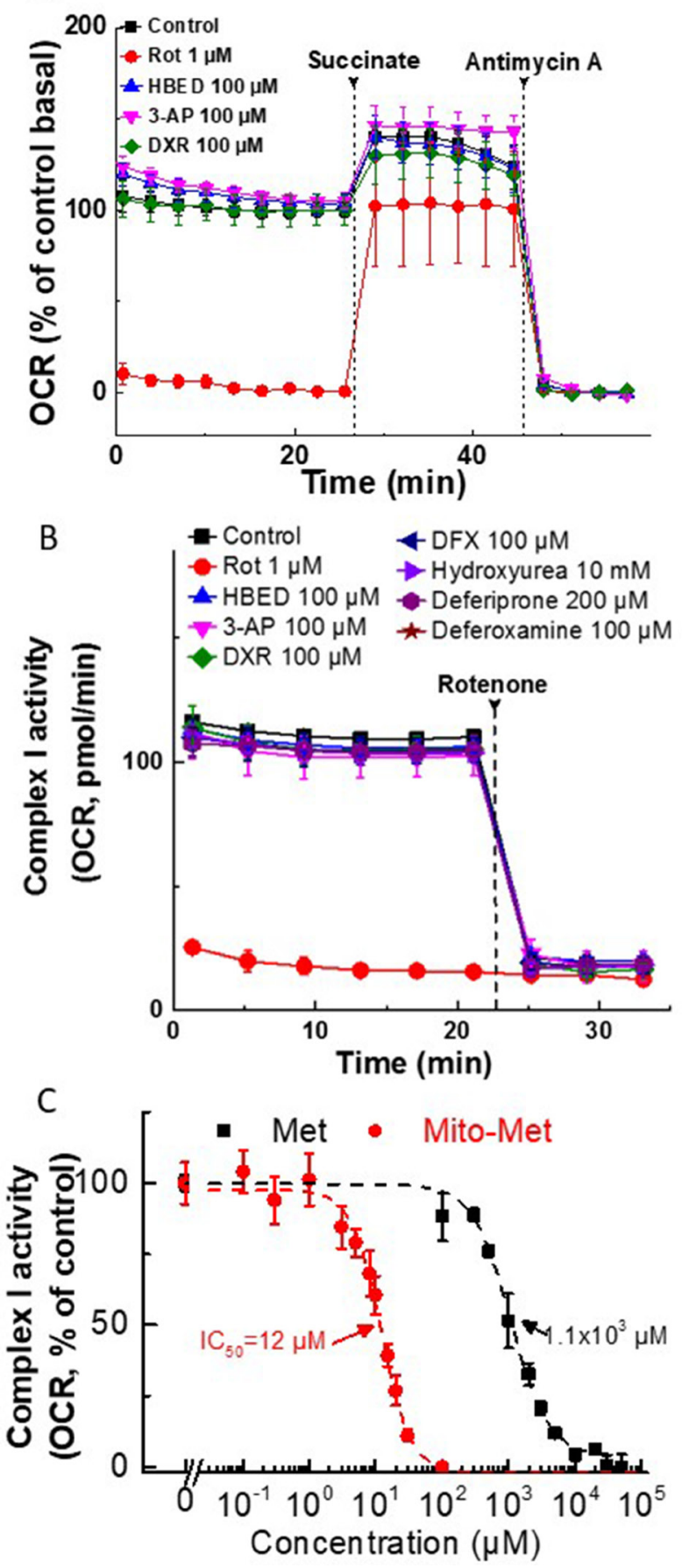

Figure 6: Effect of iron chelators and Met/Mito-Met on mitochondrial complex I activity in MiaPaCa-2 and MDAMB- 231 cells. (A) Permeabilized MiaPaCa-2 cells were assayed in medium containing $10 \mathrm{mM}$ pyruvate and $1.5 \mathrm{mM}$ malate (substrates for complex I) in mannitol and sucrose (MAS) buffer. Either rotenone (Rot, complex I inhibitor) or iron chelators were added acutely and the OCR was assayed immediately. Both succinate (substrate for complex II, $10 \mathrm{mM}$ ) and antimycin A (complex III inhibitor, $20 \mu \mathrm{M}$ ) were injected, as indicated by the dashed lines. The mitochondrial complex I-dependent oxygen consumption was monitored as OCR trace shown before succinate injection. The three iron chelators tested showed no effects on complex I activity at up to $100 \mu \mathrm{M}$ concentration. Rotenone was used as a positive control. (B) Permeabilized MDA-MB-231 cells were assayed in medium containing $10 \mathrm{mM}$ pyruvate and $1.5 \mathrm{mM}$ malate as panel A in MAS buffer. Either rotenone (Rot, complex I inhibitor) or iron chelators were added acutely, and OCR was assayed immediately. The complex I inhibitor Rot $(1 \mu \mathrm{M})$ was injected where indicated. The mitochondrial complex I-dependent oxygen consumption was monitored as shown by the OCR trace. The iron chelators tested showed no effects on complex I activity at up to a $100 \mu \mathrm{M}-10 \mathrm{mM}$ concentration. (C) The effect of Met and Mito-Met on the activity of mitochondrial complex I in human breast cancer cells. MDA-MB-231 cells were pretreated with Met or Mito-Met for $24 \mathrm{~h}$. The mitochondrial complex I OCRs are plotted against the concentration of Met or Mito-Met. Dashed lines represent the fitting curves used for determination of the $\mathrm{IC}_{50}$ values. OCR was measured as in (B). 
induced ROS formation in tumor cells (Figure 7). Thus, the combination of Met/Mito-Met and iron chelators is unlikely to enhance tumor metastasis, although this must be proven in in vivo tumor xenografts.

\section{Metformin and analogs and antitumor effects}

Metformin is weakly cationic and targets mitochondria, inhibiting complex I-dependent respiration in cancer cells [35]. However, a high concentration of Met is required to inhibit cancer cell respiration and proliferation [7]. The intracellular uptake of Met is enhanced in cancer cells exhibiting increased expression of the organic cation transporter [36]. Ovarian cancer cells with a downregulated organic cation transporter are resistant to Met toxicity [37]. In contrast to Met, Mito-Met is nearly 1,000-times more effective in inhibiting pancreatic cancer cell proliferation [7]. MitoMet is effective at low micromolar levels [7]. The cell permeability of Mito-Met is increased because of the presence of a long alkyl chain and the delocalized lipophilic cationic moiety, $\mathrm{TPP}^{+}$[7]. The mitochondrial membrane potential in cancer cells is more negative as compared with normal cell mitochondria, and the presence of permanent positive charge is a major driving force for mitochondrial accumulation [38]. Mito-Met inhibits complex I, inducing ROS and AMP-activated protein kinase (AMPK) activation and resulting in enhanced signaling and activity of antiproliferative processes. At the concentrations used in this study, Mito-Met had no effect on the growth of nontumorigenic cells [7].

A

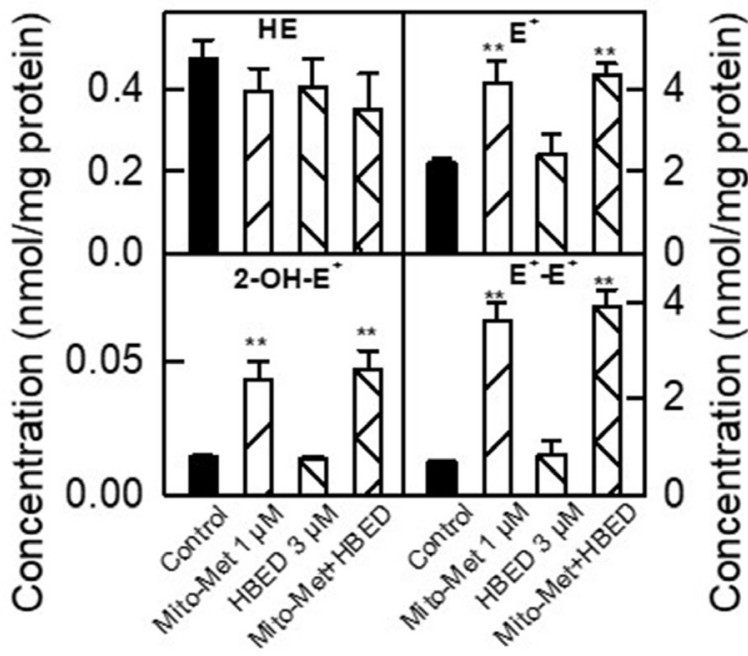

Synergistic effect of iron chelators on antitumor drugs

Synergism between the iron chelator, DFX, and conventional cytotoxic chemotherapeutics (e.g., doxorubicin, cyclophosphamide, and cisplatin or carboplatin) in the treatment of triple-negative breast cancers has previously been reported [39]. Therapeutic targeting of iron metabolism for breast cancer treatment was reported many years ago [40, 41]. In this work, we demonstrate the ability of iron chelators to synergize with relatively nontoxic and tumor-cellspecific antiproliferative agents (Met and Mito-Met). Met potentiated the antitumor effects of doxorubicin in pancreatic and breast cancer cells [42]. Thus, the combined use of conventional chemotherapeutics, iron chelators, and Met or Mito-Met is likely to be a potent antitumor cocktail. Radiation treatment exacerbated the antiproliferative effects of Met and Mito-Met in pancreatic cancer cells [7]. It would be of interest to investigate the effect of radiation on the combined effects of Met analogs and iron chelators. This proposal should, however, be tested both in vitro and in vivo prior to being translated to the clinic.

\section{Stimulation of autophagy by iron chelators and Mito-Met in cancer cells}

Iron chelators and mitochondria-targeted agents have been reported to induce autophagy in several cancer cells $[39,43-46]$. The iron chelator DFO was shown

B

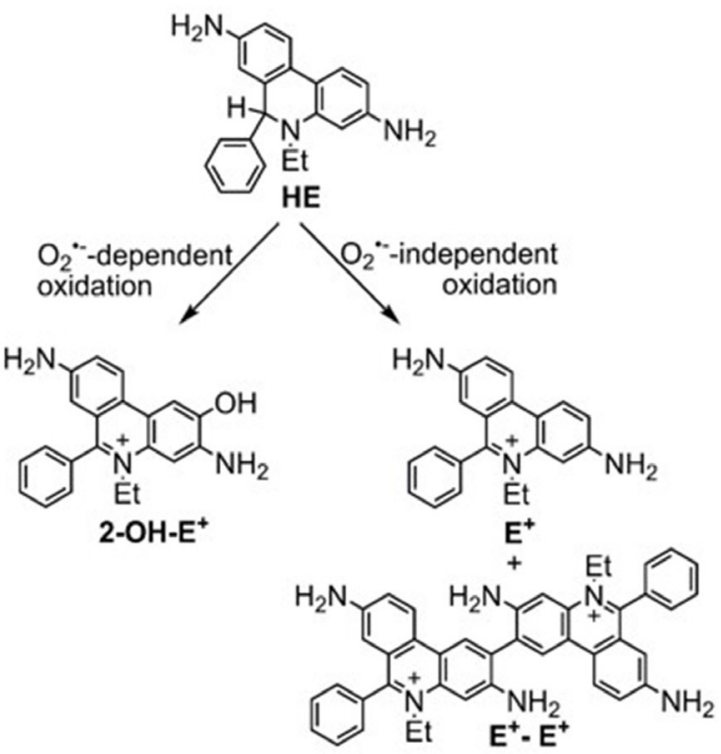

Figure 7: Characterization of intracellular oxidants induced by Mito-Met and HBED in MiaPaCa-2 cells. (A) MiaPaCa-2 cells were treated with HBED $(3 \mu \mathrm{M})$ or Mito-Met $(1 \mu \mathrm{M})$ alone or in combination for $24 \mathrm{~h}$. Next, the cells were washed free of excess Mito-Met and HBED and treated with the ROS probe, HE $(10 \mu \mathrm{M})$, for $60 \mathrm{~min}$. Cells were then lysed and analyzed by HPLC. Bar graphs show the results of quantitative analysis of intracellular levels of HE probe and oxidation/hydroxylation products formed from HE. (B) A schematic representation of the superoxide-dependent and independent pathways of HE oxidation. 2-hydroxyethidium (2-OH-E $\left.{ }^{+}\right)$is a superoxide-specific product, $\mathrm{E}^{+}$is a nonspecific oxidation product, and $\mathrm{E}^{+}-\mathrm{E}^{+}$is a product of one-electron oxidation of the probe. 
to inhibit TRAIL-mediated apoptosis via induction of autophagy flux, and chloroquine, an inhibitor of autophagy, blocks DFO-mediated tumor cell death via the autophagy pathway [44]. The anticancer agent with an iron chelating ability (di-2-pyridylketone-4,4-dimethyl3-thiosemicarbazone [Dp44mT]) activated autophagy kinase, Unk-51-like kinase, in tumor cells [45]. Recently, Mito-Met and another mitochondria-targeted agent (Mito$\mathrm{CP}$ ) were shown to stimulate mitophagy (mitochondrial autophagy) in colon cancer cells [46]. It is conceivable that iron chelators and Met analogs synergistically inhibit cell proliferation via enhanced stimulation of mitophagy in cancer cells.

\section{Potential cardioprotective effect by Met analogs and iron chelators}

Another aspect of Met analogs and iron chelators therapies of cancers is that both Met and DXR have exhibited cardioprotective effects in human and animal studies [47-49]. Thus, it is plausible that the combined use of Met analogs and iron chelators (e.g., DFX) will not only decrease the tumor proliferation (as discussed in this

A

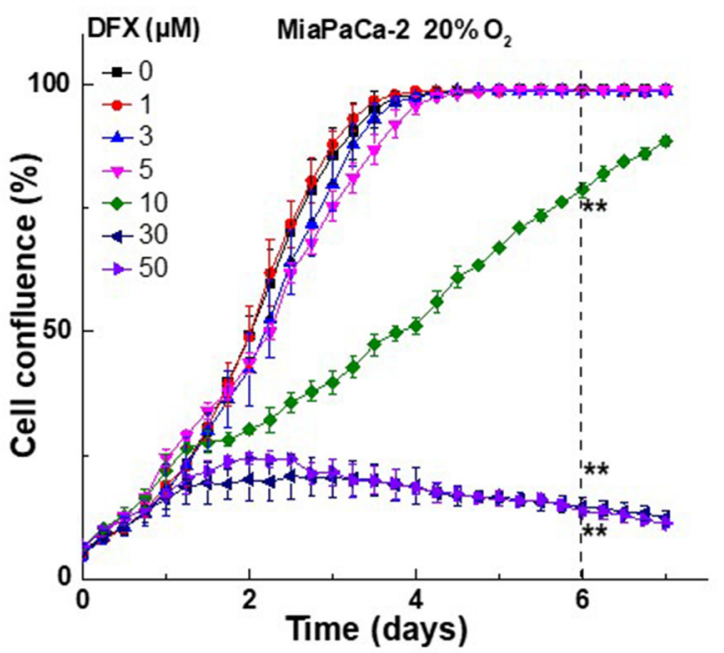

work) but could potentially protect cardiomyocytes against oxidative damage. Heart problems in doxorubicin-treated cancer patients do not manifest until many years post chemotherapy [50-52]. Children with leukemia that are treated with doxorubicin develop cardiotoxicity after they reach adulthood, and the onset and severity of the toxicity were decreased when treated with the iron chelator, DXR. In other studies, treatment with Met was shown to afford cardioprotection [53].

\section{Could copper chelators also induce a synergistic antiproliferative effect with Met analogs in cancer cells?}

Both iron and copper are important for cancer cell proliferation [54]. Whereas iron chelators (e.g., Triapine) show promise in cancer therapy, copper chelators such as penicillamine revealed an antitumor effect [54]. It has been reported that genetic perturbation of copper or decreasing copper levels with specific copper chelators inhibits growth of drug-resistant melanoma cells $[55,56]$. In this regard, it is of interest to note that metformin itself is a moderate to strong copper chelator [57], and this

B

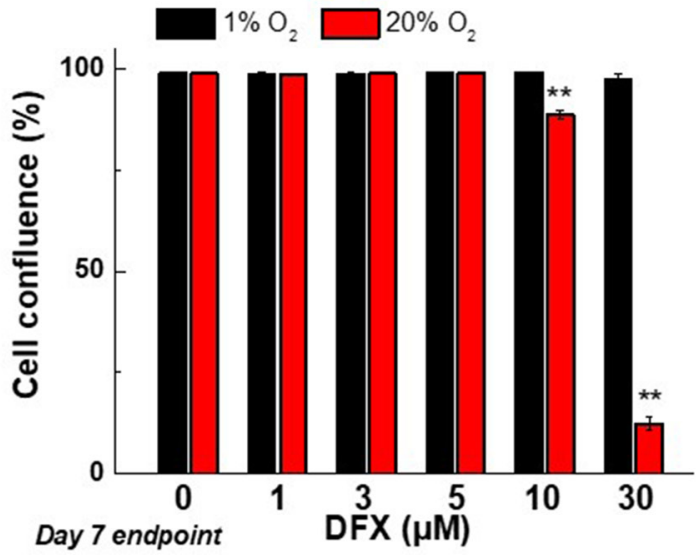

C
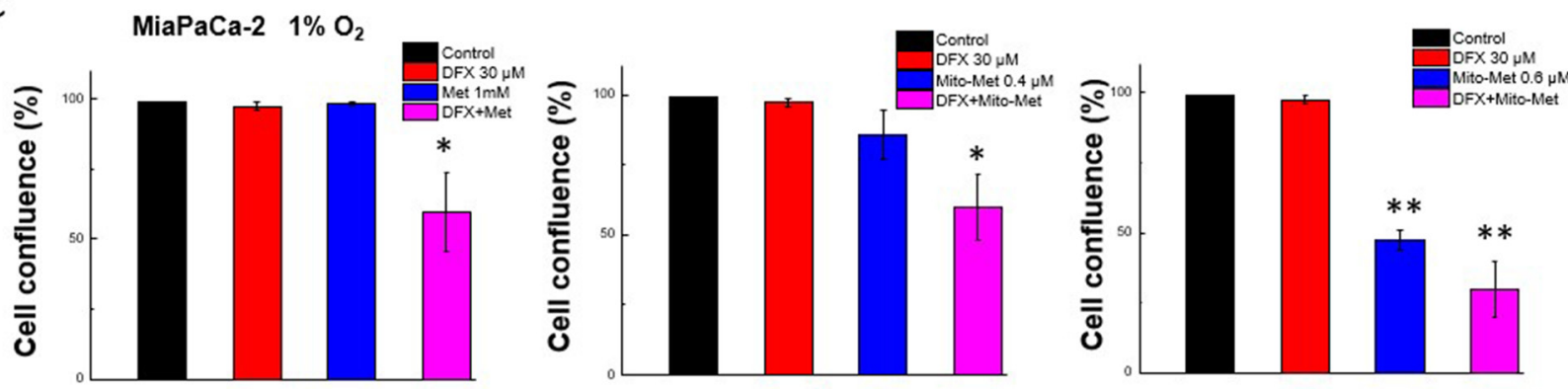

Figure 8: Effect of normoxia and hypoxia on the antiproliferative effects of DFX iron chelator, Met, and Mito-Met against MiaPaCa-2 cells. (A) MiaPaCa-2 cells cultured at 20\% oxygen were treated with DFX and cell growth was monitored continuously up to 7 days. (B) The comparison of the effects of DFX on cell proliferation under hypoxia $\left(1 \% \mathrm{O}_{2}\right)$ and normoxia $\left(20 \% \mathrm{O}_{2}\right)$ at the same treatments time point. (C) Effect of Met analogs and iron chelator, DFX, on MiaPaCa-2 cell proliferation under hypoxia (1\% $\mathrm{O}_{2}$ ) condition. Cells were treated with DFX and $\operatorname{Met}(\mathrm{C}$, left $)$ or Mito-Met $(\mathrm{C}$, middle and right $)$ independently and together, as indicated, and cell growth was shown as cell confluence. Data shown are the mean $\pm \mathrm{SD}(n=4) .\left({ }^{*} P<0.05,{ }^{* *} P<0.05\right)$ 
effect was reported to play a role in cancer cell killing [58]. Based on these results, it seems plausible that copper chelators combined with mitochondrial antitumor drugs may induce a synergistic antiproliferative effect in cancer cells. Clearly, detailed studies with copper chelators and metformin analyses are warranted.

\section{MATERIALS AND METHODS}

\section{Chemicals}

Mito-Met was synthesized and purified as reported previously [7]. Iron chelators were purchased from SigmaAldrich (St. Louis, MO, USA).

\section{Cell lines}

Human MiaPaCa-2 pancreatic cancer and wildtype and brain homing MDA-MB-231 breast cancer cells were purchased from ATCC (Manassas, VA, USA). All cells were kept frozen in liquid nitrogen and were used within 20 passages after thawing. The cells were cultured under standard conditions $\left(37^{\circ} \mathrm{C}\right.$ and $\left.5 \% \mathrm{CO}_{2}\right)$ in Dulbecco's Modified Eagle Medium (Thermo Fisher Scientific, Waltham, MA, USA, Catalog No. 11965) supplemented with $10 \%$ fetal bovine serum, 100 units/ $\mathrm{ml}$ penicillin, and $100 \mu \mathrm{g} / \mathrm{ml}$ streptomycin (Thermo Fisher Scientific, Waltham, MA, USA).

\section{Cell proliferation and clonogenic assays}

Cell proliferation was measured using a probe-free, noninvasive cellular confluence assay by the IncuCyte Live Cell System (IncuCyte FLR, Essen BioScience, Ann Arbor, MI, USA), as described previously [7]. Changes in cell confluence were used as the surrogate marker of cell proliferation.

For clonogenic assay, cells were seeded as indicated in six-well plates and treated with Mito-Met or Met for $24 \mathrm{~h}$. The plates were placed within the incubator and the cell culture media changed every 3-4 days until the control (untreated) cells formed sufficiently large clones. The cell survival fractions were calculated as previously reported [7].

\section{Mitochondrial function measurements}

The mitochondrial function was measured in real time using a Seahorse XF96 Extracellular Flux Analyzer (Agilent, North Billerica, MA, USA). Assays in intact cells were performed as reported previously [7]. The OCR derived from mitochondrial complex I and complex II activities was measured in the presence of different mitochondrial substrates, e.g., pyruvate/malate for complex I and succinate for complex II. Rotenone, malonate, and antimycin A were used as specific inhibitors of mitochondrial oxygen consumption at complexes I, II, and III, respectively.

\section{ROS and oxidation products}

ROS were measured using the probe, HE. A stock solution of HE $(20 \mu \mathrm{M})$ was prepared in deoxygenated dimethyl sulfoxide and stored in the dark at $-80^{\circ} \mathrm{C}$ until use. Previously, we showed that a global analysis of oxidation products derived from HE provides a better picture of oxidants generated intracellularly. To this end, we characterized the various oxidation products from $\mathrm{HE}$ using the appropriate standards $[65,66]$. The hydroxylated oxidation product, 2-OH-E $\mathrm{E}^{+}$, formed from $\mathrm{HE}$ reaction with $\mathrm{O}_{2}^{--}$was prepared by reacting $\mathrm{HE}$ with Fremy's salt [65]. The nonspecific, two-electron oxidation product of $\mathrm{HE}, \mathrm{E}^{+}$(bromide salt), was purchased from Sigma-Aldrich (St. Louis, MO, USA). The dimeric product $\left(\mathrm{E}^{+}-\mathrm{E}^{+}\right)$was prepared by oxidizing HE with excess ferricyanide [65]. All standards were purified by high-performance liquid chromatography (HPLC).

\section{HPLC and LC-MS/MS}

HPLC and liquid chromatography-mass spectrometry (LC-MS/MS) analyses were performed as previously described [7]. Briefly, cells were grown in $10 \mathrm{~cm}$ dishes and incubated with Mito-Met, Met, or iron chelator HBED for $24 \mathrm{~h}$ in full media. HPLC analysis was performed using Kinetex $\mathrm{C}_{18}$ column.

\section{CONCLUSIONS}

In this study, we report that the combined use of iron chelators, some of which are FDA-approved drugs, and Met analogs synergistically inhibits proliferation of pancreatic and breast cancer cells. Iron chelators previously have been shown to inhibit cancer cell proliferation when combined with conventional cytotoxic chemotherapeutics [7, 39, 59]. OXPHOS is emerging as an important target in cancer therapy [60]. The recent data suggest that iron chelators could exacerbate the antiproliferative effect of OXPHOS inhibitors in cancer cells. Here, we show that iron chelators potently sensitize and exacerbate the antiproliferative effects of relatively nontoxic mitochondria-targeted drugs in cancer cells. Although the exact molecular mechanism of action has not been determined, it is conceivable that multiple cellular targets and several mechanisms (e.g., cell cycle arrest and cell cycle dysregulation, disruption of mitochondrial redox signaling, topoisomerase inhibition and DNA damage, activation of tumor suppressor genes, endoplasmic reticulum stress, and autophagic pathways) are involved [61-64].

\section{Abbreviations}

2-OH-E ${ }^{+}$: 2-hydroxyethidium; AMPK: AMP-activated protein kinase; CI-Fa: Combination index-fraction affected; DFO: Deferoxamine; DFX: Deferasirox; Dp44mT: di-2- 
pyridylketone-4,4-dimethyl-3-thiosemicarbazone; DXR: Dexrazoxane; $\mathrm{E}^{+}$: Ethidium; $\mathrm{E}^{+}-\mathrm{E}^{+}$: Diethidium; HBED: N,N'-bis(2-hydroxyphenyl)ethylendiamine-N,N'-diacetic acid; HE: Hydroethidine; HPLC: High-performance liquid chromatography; LC-MS/MS: Liquid chromatographymass spectrometry; MAS: Mannitol and sucrose; Met: Metformin; Mito-Met: Mito-metformin; $\mathrm{O}_{2}{ }^{-}{ }^{-}$: Superoxide; OXPHOS: Oxidative phosphorylation; ROS: Reactive oxygen species; RR: Ribonucleotide reductase; $\mathrm{TPP}^{+}$: Triphenylphosphonium cation.

\section{Author contributions}

GC performed the experiments and created the figures, JZ helped write the manuscript and create the figures, $\mathrm{MH}$ synthesized the compounds and helped revise the manuscript, OO helped revise the manuscript, $\mathrm{CC}$ helped revise the manuscript, MD helped revise the manuscript, and BK conceived the idea for and wrote the manuscript.

\section{CONFLICTS OF INTEREST}

The authors declare no conflicts of interest.

\section{FUNDING}

This work was supported by the National Institutes of Health [U01 CA178960].

\section{REFERENCES}

1. Bailey C, Day C. Metformin: its botanical background. Pract Diabetes Int. 2004; 21:115-7. https://doi.org/10.1002/pdi.606

2. Graham GG, Punt J, Arora M, Day RO, Doogue MP, Duong JK, Furlong TJ, Greenfield JR, Greenup LC, Kirkpatrick CM, Ray JE, Timmins P, Williams KM. Clinical pharmacokinetics of metformin. Clin Pharmacokinet. 2011; 50:81-98. https:// doi.org/10.2165/11534750-000000000-00000. [PubMed]

3. Landman GW, Kleefstra N, van Hateren KJ, Groenier $\mathrm{KH}$, Gans RO, Bilo HJ. Metformin associated with lower cancer mortality in type 2 diabetes: ZODIAC-16. Diabetes Care. 2010; 33:322-6. https://doi.org/10.2337/dc09-1380. [PubMed]

4. Currie CJ, Poole CD, Gale EA. The influence of glucoselowering therapies on cancer risk in type 2 diabetes. Diabetologia. 2009; 52:1766-77. https://doi.org/10.1007/ s00125-009-1440-6. [PubMed]

5. Quinn BJ, Kitagawa H, Memmott RM, Gills JJ, Dennis PA. Repositioning metformin for cancer prevention and treatment. Trends Endocrinol Metab. 2013; 24:469-80. https://doi.org/10.1016/j.tem.2013.05.004. [PubMed]

6. Wang CP, Lehman DM, Lam YF, Kuhn JG, Mahalingam D, Weitman S, Lorenzo C, Downs JR, Stuart EA, Hernandez J, Thompson IM, Ramirez AG. Metformin for Reducing
Racial/Ethnic Difference in Prostate Cancer Incidence for Men with Type II Diabetes. Cancer Prev Res (Phila). 2016; 9:779-87. https://doi.org/10.1158/1940-6207.Capr-15-0425. [PubMed]

7. Cheng G, Zielonka J, Ouari O, Lopez M, McAllister D, Boyle K, Barrios CS, Weber JJ, Johnson BD, Hardy M, Dwinell MB, Kalyanaraman B. MitochondriaTargeted Analogues of Metformin Exhibit Enhanced Antiproliferative and Radiosensitizing Effects in Pancreatic Cancer Cells. Cancer Res. 2016; 76:3904-15. https://doi.org/10.1158/0008-5472.can-15-2534. [PubMed]

8. Kalyanaraman B, Cheng G, Hardy M, Ouari O, Sikora A, Zielonka J, Dwinell M. Mitochondria-targeted metformins: anti-tumour and redox signalling mechanisms. Interface Focus. 2017; 7:20160109. https://doi.org/10.1098/rsfs.2016.0109. [PubMed]

9. Jeong YK, Kim MS, Lee JY, Kim EH, Ha H. Metformin Radiosensitizes p53-Deficient Colorectal Cancer Cells through Induction of G2/M Arrest and Inhibition of DNA Repair Proteins. PLoS One. 2015; 10:e0143596. https://doi.org/10.1371/journal.pone.0143596. [PubMed]

10. Mitrakas AG, Kalamida D, Koukourakis MI. Effect of mitochondrial metabolism-interfering agents on cancer cell mitochondrial function and radio/chemosensitivity. Anticancer Drugs. 2014; 25:1182-91. https://doi. org/10.1097/cad.0000000000000152. [ $\underline{\text { PubMed] }}$

11. Le NT, Richardson DR. The role of iron in cell cycle progression and the proliferation of neoplastic cells. Biochim Biophys Acta. 2002; 1603:31-46. https://doi. org/10.1016/s0304-419x(02)00068-9. [PubMed]

12. Le NT, Richardson DR. Iron chelators with high antiproliferative activity up-regulate the expression of a growth inhibitory and metastasis suppressor gene: a link between iron metabolism and proliferation. Blood. 2004; 104:2967-75. https://doi.org/10.1182/blood-2004-05-1866. [PubMed]

13. Walsh JC, Lebedev A, Aten E, Madsen K, Marciano L, Kolb HC. The clinical importance of assessing tumor hypoxia: relationship of tumor hypoxia to prognosis and therapeutic opportunities. Antioxid Redox Signal. 2014; 21:1516-54. https://doi.org/10.1089/ars.2013.5378. [PubMed]

14. Yasui H, Matsumoto S, Devasahayam N, Munasinghe JP, Choudhuri R, Saito K, Subramanian S, Mitchell JB, Krishna MC. Low-field magnetic resonance imaging to visualize chronic and cycling hypoxia in tumor-bearing mice. Cancer Res. 2010; 70:6427-36. https://doi.org/10.1158/0008-5472. Can-10-1350. [PubMed]

15. Corce V, Gouin SG, Renaud S, Gaboriau F, Deniaud D. Recent advances in cancer treatment by iron chelators. Bioorg Med Chem Lett. 2016; 26:251-6. https://doi. org/10.1016/j.bmcl.2015.11.094. [PubMed]

16. Fryknas M, Zhang X, Bremberg U, Senkowski W, Olofsson MH, Brandt P, Persson I, D’Arcy P, Gullbo J, Nygren P, Schughart LK, Linder S, Larsson R. Iron chelators target both proliferating and quiescent cancer cells. Sci Rep. 2016; 6:38343. https://doi.org/10.1038/srep38343. [PubMed] 
17. Harima H, Kaino S, Takami T, Shinoda S, Matsumoto T, Fujisawa K, Yamamoto N, Yamasaki T, Sakaida I. Deferasirox, a novel oral iron chelator, shows antiproliferative activity against pancreatic cancer in vitro and in vivo. BMC Cancer. 2016; 16:702. https://doi.org/10.1186/s12885-0162744-9. [PubMed]

18. Roy N, Takeuchi KK, Ruggeri JM, Bailey P, Chang D, Li J, Leonhardt L, Puri S, Hoffman MT, Gao S, Halbrook CJ, Song Y, Ljungman M, et al. PDX1 dynamically regulates pancreatic ductal adenocarcinoma initiation and maintenance. Genes Dev. 2016; 30:2669-83. https://doi. org/10.1101/gad.291021.116. [PubMed]

19. Allen GF, Toth R, James J, Ganley IG. Loss of iron triggers PINK1/Parkin-independent mitophagy. EMBO Rep. 2013; 14:1127-35. https://doi.org/10.1038/embor.2013.168. [PubMed]

20. Cheng G, Zielonka M, Dranka BP, Kumar SN, Myers CR, Bennett B, Garces AM, Dias Duarte Machado LG, Thiebaut D, Ouari O, Hardy M, Zielonka J, Kalyanaraman B. Detection of mitochondria-generated reactive oxygen species in cells using multiple probes and methods: Potentials, pitfalls, and the future. J Biol Chem. 2018; 293:10363-08. https://doi.org/10.1074/jbc.RA118.003044. [PubMed]

21. Legendre C, Avril S, Guillet C, Garcion E. Low oxygen tension reverses antineoplastic effect of iron chelator deferasirox in human glioblastoma cells. BMC Cancer. 2016; 16:51. https://doi.org/10.1186/s12885-016-2074-y. [PubMed]

22. Manz DH, Blanchette NL, Paul BT, Torti FM, Torti SV. Iron and cancer: recent insights. Ann N Y Acad Sci. 2016; 1368:149-61. https://doi.org/10.1111/nyas.13008. [PubMed]

23. Zhou L, Zhao B, Zhang L, Wang S, Dong D, Lv H, Shang P. Alterations in Cellular Iron Metabolism Provide More Therapeutic Opportunities for Cancer. Int J Mol Sci. 2018; 19:E1545. https://doi.org/10.3390/ijms19051545. [PubMed]

24. Narasimhan J, Antholine WE, Chitambar CR. Effect of gallium on the tyrosyl radical of the iron-dependent M2 subunit of ribonucleotide reductase. Biochem Pharmacol. 1992; 44:24038. https://doi.org/10.1016/0006-2952(92)90686-d. [PubMed]

25. Graslund A, Sahlin M, Sjoberg BM. The tyrosyl free radical in ribonucleotide reductase. Environ Health Perspect. 1985; 64:139-49. https://doi.org/10.1289/ehp.64-1568609

26. Basuli D, Tesfay L, Deng Z, Paul B, Yamamoto Y, Ning G, Xian W, McKeon F, Lynch M, Crum CP, Hegde P, Brewer $\mathrm{M}$, Wang $\mathrm{X}$, et al. Iron addiction: a novel therapeutic target in ovarian cancer. Oncogene. 2017; 36:4089-99. https://doi.org/10.1038/onc.2017.11. [PubMed]

27. Gao J, Richardson DR. The potential of iron chelators of the pyridoxal isonicotinoyl hydrazone class as effective antiproliferative agents, IV: The mechanisms involved in inhibiting cell-cycle progression. Blood. 2001; 98:842-50. https://doi.org/10.1182/blood.v98.3.842. [PubMed]

28. Green DA, Antholine WE, Wong SJ, Richardson DR, Chitambar CR. Inhibition of malignant cell growth by
311, a novel iron chelator of the pyridoxal isonicotinoyl hydrazone class: effect on the R2 subunit of ribonucleotide reductase. Clin Cancer Res. 2001; 7:3574-9. [PubMed]

29. Yu Y, Kalinowski DS, Kovacevic Z, Siafakas AR, Jansson PJ, Stefani C, Lovejoy DB, Sharpe PC, Bernhardt PV, Richardson DR. Thiosemicarbazones from the old to new: iron chelators that are more than just ribonucleotide reductase inhibitors. J Med Chem. 2009; 52:5271-94. https://doi.org/10.1021/jm900552r. [PubMed]

30. Chitambar CR, Sax D. Regulatory effects of gallium on transferrin-independent iron uptake by human leukemic HL60 cells. Blood. 1992; 80:505-11. [라Med]

31. De Bortoli M, Taverna E, Maffioli E, Casalini P, Crisafi F, Kumar V, Caccia C, Polli D, Tedeschi G, Bongarzone I. Lipid accumulation in human breast cancer cells injured by iron depletors. J Exp Clin Cancer Res. 2018; 37:75. https://doi.org/10.1186/s13046-018-0737-z. [PubMed]

32. Kinowaki Y, Kurata M, Ishibashi S, Ikeda M, Tatsuzawa A, Yamamoto M, Miura O, Kitagawa M, Yamamoto K. Glutathione peroxidase 4 overexpression inhibits ROSinduced cell death in diffuse large B-cell lymphoma. Lab Invest. 2018; 98:609-19. https://doi.org/10.1038/s41374017-0008-1. [PubMed]

33. Dixon SJ, Lemberg KM, Lamprecht MR, Skouta R, Zaitsev EM, Gleason CE, Patel DN, Bauer AJ, Cantley AM, Yang WS, Morrison B 3rd, Stockwell BR. Ferroptosis: an irondependent form of nonapoptotic cell death. Cell. 2012; 149:1060-72. https://doi.org/10.1016/j.cell.2012.03.042. [PubMed]

34. Sayin VI, Ibrahim MX, Larsson E, Nilsson JA, Lindahl P, Bergo MO. Antioxidants accelerate lung cancer progression in mice. Sci Transl Med. 2014; 6:221ra15. https://doi. org/10.1126/scitranslmed.3007653. [PubMed]

35. Wheaton WW, Weinberg SE, Hamanaka RB, Soberanes S, Sullivan LB, Anso E, Glasauer A, Dufour E, Mutlu GM, Budigner GS, Chandel NS. Metformin inhibits mitochondrial complex I of cancer cells to reduce tumorigenesis. eLife. 2014; 3:e02242. https://doi.org/10.7554/eLife.02242. [PubMed]

36. Cai H, Zhang Y, Han TK, Everett RS, Thakker DR. Cationselective transporters are critical to the AMPK-mediated antiproliferative effects of metformin in human breast cancer cells. Int J Cancer. 2016; 138:2281-92. https://doi. org/10.1002/ijc.29965. [PubMed]

37. Segal ED, Yasmeen A, Beauchamp MC, Rosenblatt J, Pollak M, Gotlieb WH. Relevance of the OCT1 transporter to the antineoplastic effect of biguanides. Biochem Biophys Res Commun. 2011; 414:694-9. https://doi.org/10.1016/j. bbrc.2011.09.134. [PubMed]

38. Murphy MP, Smith RA. Targeting antioxidants to mitochondria by conjugation to lipophilic cations. Annu Rev Pharmacol Toxicol. 2007; 47:629-56. https://doi.org/10.1146/ annurev.pharmtox.47.120505.105110. [PubMed]

39. Tury S, Assayag F, Bonin F, Chateau-Joubert S, Servely JL, Vacher S, Becette V, Caly M, Rapinat A, Gentien D, 
de la Grange P, Schnitzler A, Lallemand F, et al. The iron chelator deferasirox synergises with chemotherapy to treat triple-negative breast cancers. J Pathol. 2018; 246:103-14. https://doi.org/10.1002/path.5104. [PubMed]

40. Torti SV, Torti FM. Cellular iron metabolism in prognosis and therapy of breast cancer. Crit Rev Oncog. 2013; 18:435-48. https://doi.org/10.1615/critrevoncog.2013007784. [PubMed]

41. Durigova A, Jacot W, Pouderoux S, Roques S, Montels F, Lamy PJ. [Iron metabolism in breast cancer: knowledge and future]. Ann Biol Clin (Paris). 2012; 70:387-96. https://doi. org/10.1684/abc.2012.0700. [PubMed]

42. Li Y, Wang M, Zhi P, You J, Gao JQ. Metformin synergistically suppress tumor growth with doxorubicin and reverse drug resistance by inhibiting the expression and function of P-glycoprotein in MCF7/ADR cells and xenograft models. Oncotarget. 2017; 9:2158-74. https://doi.org/10.18632/oncotarget.23187. [PubMed]

43. Pullarkat V, Meng Z, Donohue C, Yamamoto VN, Tomassetti S, Bhatia R, Krishnan A, Forman SJ, Synold TW. Iron chelators induce autophagic cell death in multiple myeloma cells. Leuk Res. 2014; 38:988-96. https://doi. org/10.1016/j.leukres.2014.06.005. [PubMed]

44. Moon JH, Jeong JK, Park SY. Deferoxamine inhibits TRAIL-mediated apoptosis via regulation of autophagy in human colon cancer cells. Oncol Rep. 2015; 33:1171-6. https://doi.org/10.3892/or.2014.3676. [PubMed]

45. Gutierrez E, Richardson DR, Jansson PJ. The anticancer agent di-2-pyridylketone 4,4-dimethyl-3-thiosemicarbazone (Dp44mT) overcomes prosurvival autophagy by two mechanisms: persistent induction of autophagosome synthesis and impairment of lysosomal integrity. J Biol Chem. 2014; 289:33568-89. https://doi.org/10.1074/jbc. M114.599480. [PubMed]

46. Boyle KA, Van Wickle J, Hill RB, Marchese A, Kalyanaraman B, Dwinell MB. Mitochondria-targeted drugs stimulate mitophagy and abrogate colon cancer cell proliferation. J Biol Chem. 2018; 293:14891-904. https://doi.org/10.1074/jbc.RA117.001469. [ubMed]

47. Asensio-Lopez MC, Lax A, Pascual-Figal DA, Valdes M, Sanchez-Mas J. Metformin protects against doxorubicininduced cardiotoxicity: involvement of the adiponectin cardiac system. Free Radic Biol Med. 2011; 51:1861-71. https://doi. org/10.1016/j.freeradbiomed.2011.08.015. [PubMed]

48. Lyu YL, Kerrigan JE, Lin CP, Azarova AM, Tsai YC, Ban Y, Liu LF. Topoisomerase IIbeta mediated DNA double-strand breaks: implications in doxorubicin cardiotoxicity and prevention by dexrazoxane. Cancer Res. 2007; 67:8839-46. https://doi.org/10.1158/00085472.Can-07-1649. [PubMed]

49. McGowan JV, Chung R, Maulik A, Piotrowska I, Walker JM, Yellon DM. Anthracycline Chemotherapy and Cardiotoxicity. Cardiovasc Drugs Ther. 2017; 31:63-75. https://doi.org/10.1007/s10557-016-6711-0. [PubMed]

50. Sorensen K, Levitt GA, Bull C, Dorup I, Sullivan ID. Late anthracycline cardiotoxicity after childhood cancer: a prospective longitudinal study. Cancer. 2003; 97:1991-8. https://doi.org/10.1002/cncr.11274. [PubMed]

51. Iarussi D, Indolfi P, Casale F, Martino V, Di Tullio MT, Calabro R. Anthracycline-induced cardiotoxicity in children with cancer: strategies for prevention and management. Paediatr Drugs. 2005; 7:67-76. https://doi. org/10.2165/00148581-200507020-00001. [PubMed]

52. Lipshultz SE, Lipsitz SR, Sallan SE, Dalton VM, Mone SM, Gelber RD, Colan SD. Chronic progressive cardiac dysfunction years after doxorubicin therapy for childhood acute lymphoblastic leukemia. J Clin Oncol. 2005; 23:2629-36. https://doi.org/10.1200/jco.2005.12.121. [PubMed]

53. Zilinyi R, Czompa A, Czegledi A, Gajtko A, Pituk D, Lekli I, Tosaki A. The Cardioprotective Effect of Metformin in Doxorubicin-Induced Cardiotoxicity: The Role of Autophagy. Molecules. 2018; 23:E1184. https://doi. org $/ 10.3390 /$ molecules23051184. [PubMed]

54. Yu Y, Wong J, Lovejoy DB, Kalinowski DS, Richardson DR. Chelators at the cancer coalface: desferrioxamine to Triapine and beyond. Clin Cancer Res. 2006; 12:6876-83. https://doi.org/10.1158/1078-0432.Ccr-06-1954. [PubMed]

55. Brady DC, Crowe MS, Greenberg DN, Counter CM. Copper Chelation Inhibits BRAFV600E-Driven Melanomagenesis and Counters Resistance to BRAFV600E and MEK1/2 Inhibitors. Cancer Res. 2017; 77:6240-52. https://doi. org/10.1158/0008-5472.CAN-16-1190. [PubMed]

56. Brady DC, Crowe MS, Turski ML, Hobbs GA, Yao X, Chaikuad A, Knapp S, Xiao K, Campbell SL, Thiele DJ, Counter CM. Copper is required for oncogenic BRAF signalling and tumorigenesis. Nature. 2014; 509:492-6. https://doi.org/10.1038/nature13180. [PubMed]

57. Repiscak P, Erhardt S, Rena G, Paterson MJ. Biomolecular mode of action of metformin in relation to its copper binding properties. Biochemistry. 2014; 53:787-95. https:// doi.org/10.1021/bi401444n. [PubMed]

58. Muller S, Versini A, Sindikubwabo F, Belthier G, Niyomchon S, Pannequin J, Grimaud L, Caneque T, Rodriguez R. Metformin reveals a mitochondrial copper addiction of mesenchymal cancer cells. PLoS One. 2018; 13:e0206764. https://doi.org/10.1371/journal.pone.0206764. [PubMed]

59. Shinoda S, Kaino S, Amano S, Harima H, Matsumoto T, Fujisawa K, Takami T, Yamamoto N, Yamasaki T, Sakaida I. Deferasirox, an oral iron chelator, with gemcitabine synergistically inhibits pancreatic cancer cell growth in vitro and in vivo. Oncotarget. 2018; 9:28434-44. https://doi.org/10.18632/oncotarget.25421. [PubMed]

60. Ashton TM, McKenna WG, Kunz-Schughart LA, Higgins GS. Oxidative Phosphorylation as an Emerging Target in Cancer Therapy. Clin Cancer Res. 2018; 24:2482-90. https://doi.org/10.1158/1078-0432.Ccr-17-3070. [PubMed]

61. Chaston TB, Lovejoy DB, Watts RN, Richardson DR. Examination of the antiproliferative activity of iron chelators: multiple cellular targets and the different mechanism of action of triapine compared with desferrioxamine and the 
potent pyridoxal isonicotinoyl hydrazone analogue 311 . Clin Cancer Res. 2003; 9:402-14. [PubMed]

62. Le NT, Richardson DR. Potent iron chelators increase the mRNA levels of the universal cyclin-dependent kinase inhibitor p21(CIP1/WAF1), but paradoxically inhibit its translation: a potential mechanism of cell cycle dysregulation. Carcinogenesis. 2003; 24:1045-58. https://doi.org/10.1093/carcin/bgg042. [PubMed]

63. Rao VA, Klein SR, Agama KK, Toyoda E, Adachi N, Pommier Y, Shacter EB. The iron chelator Dp44mT causes DNA damage and selective inhibition of topoisomerase IIalpha in breast cancer cells. Cancer Res. 2009; 69:948-57. https://doi.org/10.1158/0008-5472.Can-08-1437. [PubMed]

64. Lui GY, Kovacevic Z, Richardson V, Merlot AM, Kalinowski DS, Richardson DR. Targeting cancer by binding iron: Dissecting cellular signaling pathways. Oncotarget. 2015; 6:18748-79. https://doi.org/10.18632/ oncotarget.4349. [PubMed]

65. Zielonka J, Kalyanaraman B. Hydroethidine- and MitoSOXderived red fluorescence is not a reliable indicator of intracellular superoxide formation: another inconvenient truth. Free Radic Biol Med. 2010; 48:983-1001. https://doi. org/10.1016/j.freeradbiomed.2010.01.028. [PubMed]

66. Kalyanaraman B, Darley-Usmar V, Davies KJ, Dennery PA, Forman HJ, Grisham MB, Mann GE, Moore K, Roberts LJ 2nd, Ischiropoulos H. Measuring reactive oxygen and nitrogen species with fluorescent probes: challenges and limitations. Free Radic Biol Med. 2012; 52:1-6. https://doi. org/10.1016/j.freeradbiomed.2011.09.030. [PubMed] 